\title{
Internal nitride formation during gas-phase thermal nitridation of titanium
}

\author{
P.K. Ajikumar, ${ }^{\mathrm{a}, *}$ M. Kamruddin, ${ }^{\mathrm{a}}$ P. Shankar, ${ }^{\mathrm{a}}$ Ramakrishna Gouda, ${ }^{\mathrm{b}}$ \\ A.K. Balamurugan, ${ }^{\mathrm{a}}$ R. Nithya, ${ }^{\mathrm{a}}$ A.K. Tyagi, ${ }^{\mathrm{a}}$ V. Jayaram, ${ }^{\mathrm{b}}$ S.K. Biswas ${ }^{\mathrm{b}}$ and Baldev Raj ${ }^{\mathrm{a}}$ \\ ${ }^{a}$ Metallurgy and Materials Group, Indira Gandhi Centre for Atomic Research, Kalpakkam 603102, India \\ ${ }^{\mathrm{b}}$ Indian Institute of Science, Bangalore 560012, India
}

Received 13 February 2009; revised 16 April 2009; accepted 17 April 2009

Available online 22 April 2009

\begin{abstract}
Titanium nitride surface layers were prepared by gas-phase thermal nitridation of pure titanium in an ammonia atmosphere at $1373 \mathrm{~K}$ for different times. In addition to the surface nitride layer, nitride/hydride formation was observed in the bulk of the specimen. The cross-section of the specimen was characterized by various techniques such as optical microscopy, scanning electron microscopy, energy dispersive X-ray spectroscopy, secondary ion mass spectrometry and nanomechanical testing, and the mechanism of formation of these phases is discussed.
\end{abstract}

(C) 2009 Acta Materialia Inc. Published by Elsevier Ltd. All rights reserved.

Keywords: Titanium nitride; Hardness; SIMS; Nanoindentation; SEM

Titanium and its alloys are extensively used in the aerospace and automobile industries because of their high specific strength and good mechanical properties. However, one of the major constraints in the wider application of titanium alloys is their poor galling resistance in sliding contact with other metals under load. Surface engineering is a well-established technique to overcome this problem and to improve the tribological properties of titanium and its alloys [1].

Titanium nitrides possess high hardness and elastic modulus combined with low coefficient of friction and good corrosion resistance [2]. These properties of TiN have prompted the use of nitrided Ti surfaces for enhanced performance under erosion or erosion-corrosion service conditions. In addition, nitrided Ti surfaces have good biocompatibility and hence have potential as implant materials, particularly for components subjected to erosion wear conditions $[3,4]$. The presence of TiN/ $\mathrm{Ti}_{2} \mathrm{~N}$ layers at the surface of the nitrided specimens is reported to result in better adhesion of fibroblast cells compared to an untreated Ti substrate $[5,6]$.

The strong affinity between nitrogen and titanium provides the driving force to form $\mathrm{TiN}$ and $\mathrm{Ti}_{2} \mathrm{~N}$ phases

\footnotetext{
*Corresponding author. Tel./fax: +91 4427480081; e-mail: pkajikumar@gmail.com
}

at the surface on nitridation. From the Ti-N phase diagram it is known that $\mathrm{Ti}$ exhibits a large solubility for nitrogen at high temperatures [7]. Several techniques, including plasma nitriding, ion implantation, gas nitriding, laser nitriding and electrochemical surface nitriding, have been employed for nitriding titanium and titanium alloys [8-13]. Among these, gas nitriding and plasma nitriding are considered to be promising methods for engineering and biomedical applications because these processes are independent of the geometry of the samples. Furthermore, using these processes it is possible to achieve large nitriding depths, compared to other methods, giving a higher reserve for wear applications.

In the present study, gas-phase thermal nitridation using ammonia gas as the nitrogen source in a thermogravimetric analysis-mass spectrometry (TGA-MS) system was carried out. Detailed analysis by X-ray diffraction (XRD), scanning electron microscopy (SEM), energy dispersive X-ray spectroscopy (EDX), secondary ion mass spectrometry (SIMS) and nanoindentation studies, with more emphasis on the examination of the cross-section of the specimens, was undertaken.

The nitridation experiments were carried out in a home assembled TGA-MS system [14]. The detailed experimental procedure was reported earlier [10]. For the sake of completeness, a brief description is given here. Pure Ti specimens were polished and cleaned 
before being exposed to a nitriding environment. These samples were subjected to nitridation at $1373 \mathrm{~K}$ for periods of 5 and $10 \mathrm{~h}$ in an ammonia atmosphere with a flow rate of $15 \mathrm{sccm}$. The weight gain of the samples during nitridation was monitored continuously. The nitrided specimens were characterized by XRD (STOE, Germany) for phase identification. The XRD data were collected in powder mode (PXRD) and glancing incidence mode (GIXRD) for bulk and surface analysis, respectively. Surface and cross-sectional microstructures were studied by SEM (Philips GX 30 ESEM). The Ti:N ratio at different nitrided zones was estimated by cross-sectional EDX, attached to the scanning electron microscope. Elastic modulus and hardness along the crosssection of the specimens were measured by nanoindentation (Hysitron, USA). Loading and unloading curves are plotted to assess the elastic recovery at different nitridation zones along the cross-section of the specimen. Titanium, nitrogen and hydrogen imaging was carried out over the cross-section by SIMS (Cameca, France).

The weight gain of the specimens during nitridation was measured online by TGA. The specimen (initial weight $1141.9 \mathrm{mg}$ ) treated at $1373 \mathrm{~K}$ for $10 \mathrm{~h}$ had a weight gain of $1.86 \%$ and the one treated for $5 \mathrm{~h}$ gained $1.46 \%$. This gain in weight during the process indicates a substantial intake of gaseous species into the sample (i.e. nitrogen and hydrogen, the cracking products of ammonia). PXRD patterns [10] clearly identified that the nitrided surface layer predominantly consists of TiN phase with a minor contribution from $\mathrm{Ti}_{2} \mathrm{~N}$. GIXRD [10] studies, however, indicated that the submicron surface layer is almost pure TiN.

In order to study the cross-sectional microstructure and the mechanical properties of the phases present, optical microscopy, SEM, EDX, SIMS and nanoindentation techniques were employed. Figure 1 shows the optical micrograph of the cross-section from a sample nitrided for $10 \mathrm{~h}$. It reveals a nitrided surface layer, which is bright and around $75 \mu \mathrm{m}$ thick. Below the outer nitride layer a darker phase running almost parallel to the surface and channeling towards the interior (as indicated by small arrow marks) is seen. A two-phase microstructural contrast is clearly observed in the bulk beyond the interface. The area fraction, and hence the volume fraction, of the different phases was estimated using image analysis software, and it was found that the darker phase comprises around $5 \%$ of the surface area. Similar observations were also made for the $5 \mathrm{~h}$

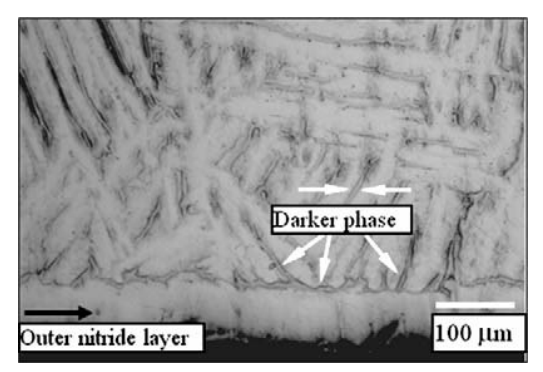

Figure 1. Cross-sectional optical micrograph of specimen nitrided at $1373 \mathrm{~K}$ for $10 \mathrm{~h}$. treated specimen except for the thickness of the outer layer, which was measured to be about $55 \mu \mathrm{m}$. Further investigations were carried out on the $10 \mathrm{~h}$ treated specimen.

Nanoindentation studies were also carried out along the cross-section of the specimen. Figure 2a illustrates the variation in hardness as well as elastic modulus along the interior region. The optical micrograph of the corresponding regions is shown below (indicated by the dotted line within the box). At the lighter regions the hardness and elastic modulus were around 10 and $135 \mathrm{GPa}$, respectively. Although these values are lower than previously reported for $\mathrm{TiN}$, it can be assumed that these are partially nitrided regions [15]. In the darker region, these values fall to 3.5 and $100 \mathrm{GPa}$, respectively. This hardness value matches well with the reported hardness value of titanium hydride [16]. Figure $2 \mathrm{~b}$ illustrates similar nanoindentation measurements covering a wider region, i.e. the nitrided outer layer, the partially nitrided region and the darker phase. The outer nitrided layer shows hardness and elastic modulus values of around 15 and $180 \mathrm{GPa}$, respectively. This is comparable to the reported data $[17,18]$, though these values vary over a wide range depending upon the methods of preparation and the process parameters. The observations on the other two regions are identical to that of Figure 2a. The load-displacement curves obtained during nanoindentation at different regions are shown in Figure 2c. The difference in hardness of the regions is apparent from the large difference in the depth of indentation for the same applied load and from the varying degrees of elastic recovery during unloading. At the hydrided zone, the indentation depth was around $240 \mathrm{~nm}$ with the maximum applied load of $5000 \mu \mathrm{N}$ followed by a minimum elastic recovery $(\sim 20 \%)$ during unloading. In the partially nitrided region, the depth was around $160 \mathrm{~nm}$ for the same applied load and there was a substantial elastic recovery $(\sim 35 \%)$ during unloading. For the completely nitrided uppermost region, the penetration depth was only about $140 \mathrm{~nm}$ and almost 50\% recovery upon unloading was observed.

The cross-section of the specimen was subjected to elemental image mapping by SIMS. A small area covering the partially nitrided zones and narrow dark channels was imaged for nitrogen and hydrogen (Fig. 3a and $b$, respectively). The images of nitrogen and hydrogen are complementary to each other. The corresponding line scan as indicated in the image was also plotted against distance (Fig. 3c). This observation clearly indicated the formation of nitrogen-rich and hydrogen-rich regions along the cross-section.

In order to substantiate the findings from the nanoindentation and SIMS measurements, these regions were further investigated by EDX line scan analysis. The SEM image and the corresponding concentration profile of titanium and nitrogen up to a depth of $\sim 300 \mu \mathrm{m}$ are shown in Figure 4a and $b$. The line profiles indicate that at the outer surface of the specimen, the concentrations of Ti and $\mathrm{N}$ are almost same, suggesting the presence of stoichiometric TiN (this was also evident from GIXRD [10]). The concentration of nitrogen decreases rapidly towards the interior, showing the formation of sub-stoi- 

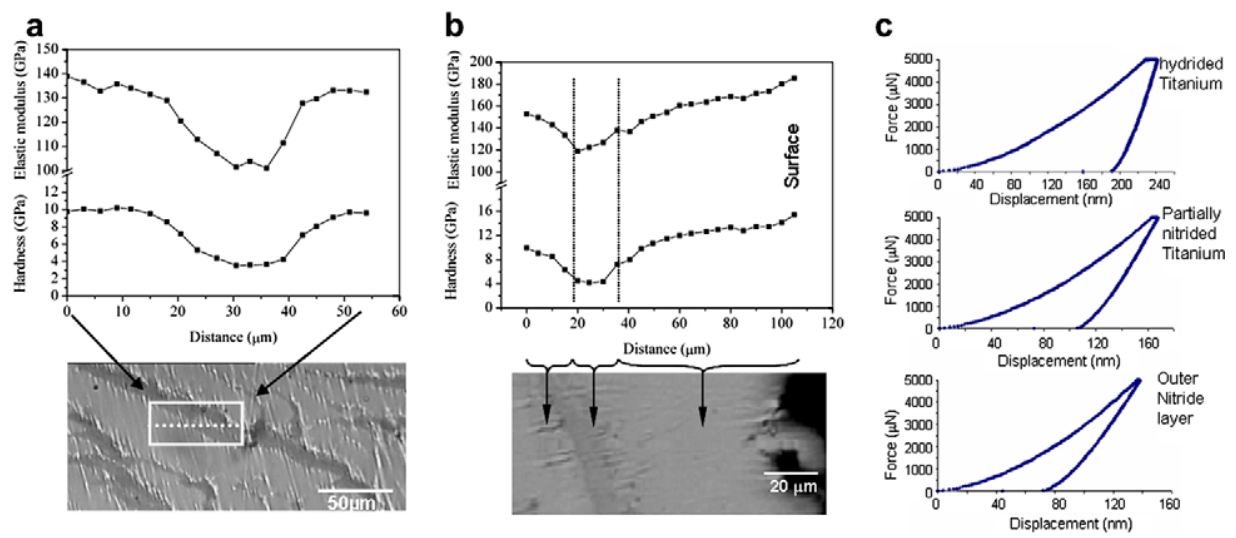

Figure 2. Elastic modulus and hardness measured using nanoindentation (a) at bulk, (b) towards the surface of the specimen and (c) forcedisplacement curves at different regions of the nitrided specimen.
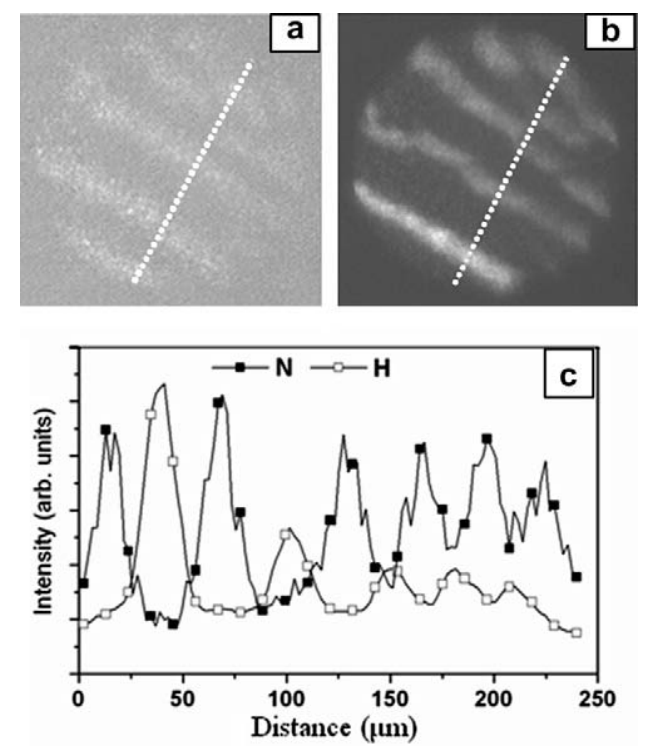

Figure 3. Elemental imaging by SIMS for (a) nitrogen and (b) hydrogen over a $250 \mu \mathrm{m}$ area and (c) the corresponding intensity profile along the dotted lines marked in the images.

chiometric $\mathrm{TiN}$ or $\mathrm{Ti}_{2} \mathrm{~N}$ or the precipitation of these compounds in a Ti matrix.

From the above observations, it is confirmed that a three-phase region - a completely nitrided outer layer, partially nitrided interior regions and narrow channels of titanium hydride - are formed during the nitridation process. For the specimen nitrided for $10 \mathrm{~h}$, the total weight gain is $21.28 \mathrm{mg}$. Bearing in mind the volume fraction of hydride $(\sim 5 \%)$ from the image analysis and the ratio of atomic weight of hydrogen to nitrogen, it can be safely assumed that this weight gain is due to uptake of nitrogen. Converting this weight gain into the number of nitrogen atoms gives a value of $\sim 9.2 \times 10^{20}$ atoms (sample size $12.5 \times 10 \times 2 \mathrm{~mm}^{3}$ ). This would result in a very high concentration of nitrogen at the surface, exceeding the solubility limit and providing a very strong driving force for surface nitridation. In addition, a substantial amount of nitrogen and hydrogen would diffuse into the bulk at the nitriding temperature.

The titanium-nitrogen system has been extensively studied by Strafford et al. [19], who reported a parabolic
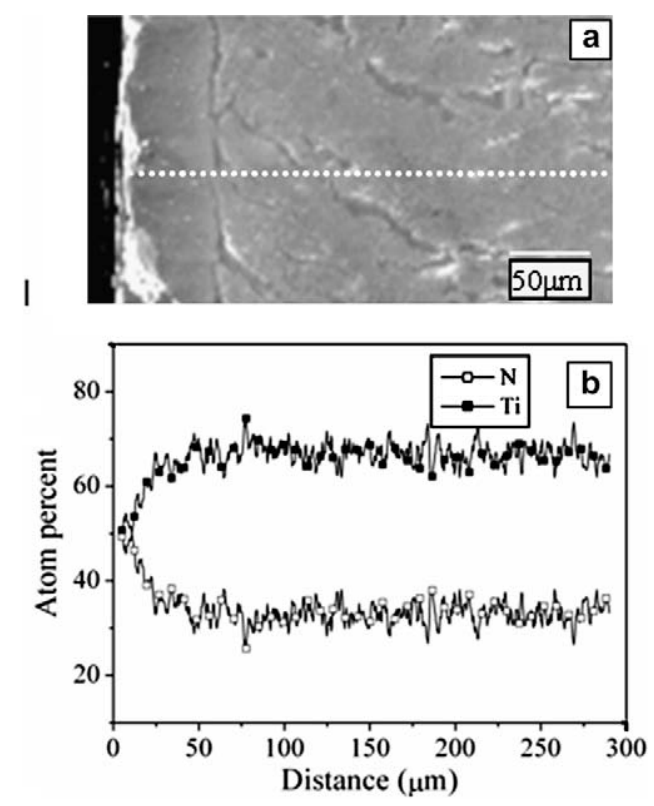

Figure 4. (a) Cross-section SEM micrograph and (b) the corresponding EDX line graph from the surface of the sample.

weight gain rate for the entire exposure period. From the Ti-N binary phase diagram [7], it is clear that the $\mathrm{N}$ solubility in $\alpha$-Ti is quite high at high temperatures (about 23 at. $\%$ of $\mathrm{N}$ above $1323 \mathrm{~K}$ ) and drops at low temperatures (about 5 at. $\% 773 \mathrm{~K}$ ). On heating pure Ti specimen to the nitriding temperature of $1373 \mathrm{~K}, \alpha$-Ti transforms to $\beta$-Ti. The required nitrogen concentration to maintain the $\alpha$ phase is 5 at. $\%$ at $1373 \mathrm{~K}$ [7]. The total weight gain over the entire nitriding period of $10 \mathrm{~h}(21.28 \mathrm{mg})$ corresponds to $\sim 6$ at. $\%$ for the entire Ti specimen. Considering the formation of the nitride layer at the surface and the resulting slow inward diffusion of nitrogen, the bulk of the specimen would remain mostly in $\beta$ phase at the nitriding temperature since the presence of nitrogen will be much lower than 5 at.\%. Upon cooling it reverts back to $\alpha-\mathrm{Ti}$ and it is likely that the dissolved nitrogen in the bulk could result in the partial nitridation of the bulk material since the solubility of nitrogen in titanium is drastically reduced at lower temperatures. Thus the measured weight 
gain should be the sum of two different contributions, namely the external scaling and partial internal nitridation in the bulk. Strafford et al. [19] concluded that the mechanism of nitridation involves an inward diffusion of nitrogen and this process is limited by the rate of diffusion of nitrogen which is slower once a nitride layer forms at the surface. Buscaglia et al. [20] studied the high-temperature behaviour of $\mathrm{Nb}-\mathrm{Ti}$ alloys of various concentrations in a nitrogen atmosphere. Their $\mathrm{Ti}(90)-\mathrm{Nb}(10)$ sample showed, over and above the complete nitridation of the outer layer, precipitation of titanium nitride needles throughout the interior region. McDonald et al. [21] also studied the reaction of nitrogen with titanium at high temperatures. They concluded that the inward diffusion of nitrogen is the dominant mass transfer process during nitridation, and that a nitrogen concentration gradient and a corresponding change in hardness exist across all phases after nitridation. A systematic investigation of the titanium-nitrogen system and the phase formation in the sub-nitride regions was carried out by Lengauer [22]. The outermost layer was made of $\mathrm{TiN}_{1-x}$ at all temperatures. He has also observed $\mathrm{Ti}_{4} \mathrm{~N}_{3-x}, \mathrm{Ti}_{3} \mathrm{~N}_{2-x}$ and $\mathrm{Ti}_{2} \mathrm{~N}$ phases at different depths. There was no trace of $\mathrm{Ti}_{2} \mathrm{~N}$ in the specimens treated at and above $1353 \mathrm{~K}$. This confirms that the $\mathrm{Ti}_{2} \mathrm{~N}$ observed in our sample must have formed during cooling. In addition, Lengauer estimated the nitrogen content in the nitrides, which varied from $\sim 30 \%$ for $\mathrm{Ti}_{2} \mathrm{~N}$ to $\sim 37 \%$ for $\mathrm{TiN}_{1-x}$.

Considering these observations [7,19-22] and a careful examination of our nanoindentation, SIMS and EDX results, we were able to deduce the mechanism of formation of three regions upon nitridation of $\mathrm{Ti}$ in $\mathrm{NH}_{3}$ atmosphere. The continuous diffusion of $\mathrm{N}$ in $\mathrm{Ti}$, at high temperature, leads to the formation of a nitride layer at the surface as well as its dissolution in the bulk. SEM and nanoindentation results show that the nitrided surface layer is around $75 \mu \mathrm{m}$ thick. A gradient in hardness as well as a change in concentration of Ti and N (Figs. $2 b$ and $4 b$ ) exist even along this layer, indicating that this layer is also not single phase. We assume that this phase consists of a thin layer of TiN at the outer surface, followed by a mixture of sub-stoichiometric $\mathrm{TiN}$ and $\mathrm{Ti}_{2} \mathrm{~N}$. If we assume that the nitrogen requirement on average is 33 at. $\%$ (from Ref. [22]) for the outer $75 \mu \mathrm{m}$ layer, the nitrogen requirement is of the order of $7 \times 10^{20}$ atoms for a specimen of dimensions $12.5 \times 10 \times 2 \mathrm{~mm}^{3}$. The total nitrogen intake is calculated to be around $9.2 \times 10^{20}$ atoms (neglecting the weight of hydrogen) from the TGA weight gain measurement. This means that of the order of $2.2 \times 10^{20}$ excess nitrogen atoms are dissolved in the bulk, which are available for internal nitriding. They are unlikely to form the nitride phase at $1373 \mathrm{~K}$ since the solubility of nitrogen in Ti is around 23 at.\% at that temperature [7]. The nitride formed inside the bulk is probably due to precipitation upon cooling since the solubility of $\mathrm{N}$ in Ti reduces drastically at lower temperatures [7]. The dissolved nitrogen in the sample will be used up for the nucleation and growth of nitride phases upon cooling. Simultaneously the dissolved hydrogen also became segregated in narrow channels to form titanium hydride.
In conclusion, nitridation of titanium was carried out in an ammonia atmosphere at $1373 \mathrm{~K}$ for 5 and $10 \mathrm{~h}$ in a TGA-MS system. In addition to the $\mathrm{TiN} / \mathrm{Ti}_{2} \mathrm{~N}$ surface layer, titanium nitride/hydride phase formation was observed in the bulk of the specimens. Cross-sectional examination of the specimen by optical microscopy, SEM, EDX, SIMS and nanoindentation revealed a three-phase microstructure with a completely nitrided outer layer at the surface followed by a narrow hydride phase and partially nitrided and hydrided precipitates throughout the bulk. The measured hardness and elastic modulus also complement the above inferences of the formation of a completely nitrided outer layer and partially nitrided internal regions separated by narrow hydride channels.

[1] T. Bell, H. Dong, in: Proceedings of the International Conference on Advances in Surface Treatment: Research \& Applications (ASTRA), 2003, Hyderabad, India, p. 12.

[2] Shanyong Zhang, Weiguang Zhu, J. Mater. Process. Technol. 39 (1993) 165.

[3] Y. Tamura, A. Yokoyama, F. Watari, T. Kawasaki, Dent. Mater. J. 21 (4) (2002) 355.

[4] S. Piscanec, L. Colombi Ciacchi, E. Vesselli, G. Comelli, O. Sbaizero, S. Meriani, Acta Mater. 52 (5) (2004) 1237.

[5] E. Czarnowska, T. Wierzchoń, A. Maranda-Niedbała, J. Mater. Process. Technol. 92-93 (1999) 190.

[6] B. Groessner-Schreiber, A. Neubert, W.-D. Muller, M. Hopp, M. Griepentrog, K.-P. Lange, J. Biomed. Mater. Res. A 64A (2003) 591.

[7] H.A. Wriedt, J.L. Murray, in: T.B. Massalski (Ed.), Binary Alloy Phase Diagrams, vol. 3, ASM, Metals Park, $\mathrm{OH}, 1986$, p. 2705.

[8] S.C. Mishra, B.B. Nayak, B.C. Mohanty, B. Mills, J. Mater. Process. Technol. 132 (1-3) (2003) 143.

[9] Y. Kasukabe, J.J. Wang, T. Yamamura, S. Yamamoto, Y. Fujino, Thin Solid Films 464 465 (2004) 180.

[10] P.K. Ajikumar, M. Kamruddin, R. Nithya, P. Shankar, S. Dash, A.K. Tyagi, Baldev Raj, Scripta Mater. 51 (2004) 361.

[11] Y. Fu, A.W. Batchelor, Wear 214 (1) (1998) 83.

[12] T. Goto, M. Tada, Y. Ito, Electrochim. Acta $39(8 / 9)$ (1994) 1107.

[13] A. Zhecheva, W. Sha, S. Malinov, A. Long, Surf. Coat. Technol. 200 (7) (2005) 2192.

[14] M. Kamruddin, P.K. Ajikumar, S. Dash, A.K. Tyagi, Baldev Raj, Bull. Mater. Sci. 26 (4) (2003) 449.

[15] Te-Hua Fang, Sheng-Rui Jian, Der-San Chuu, Appl. Surf. Sci. 228 (2004) 365.

[16] J.J. Xu, H.Y. Cheung, S.Q. Shi, J. Alloys Compds. 436 (2007) 82.

[17] G.B. de Souza, C.E. Foerster, S.L.R. da Silva, F.C. Serbena, C.M. Lepienski, C.A. dos Santos, Surf. Coat. Technol. 191 (2005) 76.

[18] C.-H. Ma, J.-H. Huang, H. Chen, Surf. Coat. Technol. 200 (2006) 3868.

[19] K.N. Strafford, J.M. Towell, Oxid. Metals 10 (1) (1976) 41.

[20] V. Buscaglia, A. Martinelli, R. Musenich, W. Mayr, W. Lengauer, J. Alloys Compds. 283 (1999) 241.

[21] N.R. Mcdonald, G.R. Wallwork, Oxid. Metals 2 (3) (1970) 263

[22] W. Lengauer, Acta Metall. Mater. 39 (12) (1991) 2985. 